Bundesgesundheitsbl 2021 · 64:108-125 https://doi.org/10.1007/s00103-020-03258-w c) Springer-Verlag GmbH Deutschland, ein Teil von Springer Nature 2020

\section{Einleitung}

Gemäß $\$ \$ 16$ und 19 TFG sind Rückverfolgungsverfahren (RVV) durchzuführen. Die Überprüfung des Verdachts einer Infektion bei einer spendenden Person und/ oder der Möglichkeit einer Infektionsübertragung durch Blutprodukte richtet sich nach dem Stand der wissenschaftlichen Erkenntnis. Die letzte Aktualisierung erfolgte mit dem Votum 47 des Arbeitskreises Blut.

Die Einführung neuer Testverfahren und neuer Anforderungen an das Spendenscreening erforderte eine Neufassung des Votums.

Das Votum weist ausdrücklich die Verfahrensweisen für Infektionen mit dem humanen Immunschwächevirus (HIV), dem Hepatitis-C-Virus (HCV), dem Hepatitis-B-Virus (HBV), dem Hepatitis-EVirus (HEV) und dem West-Nil-Virus (WNV) aus. Es kann analog auch bei anderen Infektionen mit potenziell schwerwiegendem Verlauf angewendet werden.

Für die Vorgehensweise bei Variante Creutzfeldt-Jakob-Krankheit (vCJK) im Zusammenhang mit Blut, Plasma und Blutprodukten wurde ein separates Votum verabschiedet (V 46).

Das Votum gliedert sich in einen ersten Teil, in dem die RVV erläutert werden. In den Anhängen A, B, C, D und E werden die Untersuchungsabläufe für HIV-, HBV-, HCV-, HEV- und WNV-Infektionen bei der spendenden Person schematisch dargestellt und Testsensitivitäten festgelegt.

\title{
Verfahren zur Rückverfolgung (Look Back) gemäß § 19 Transfusionsgesetz
}

\author{
Bei der 89. Sitzung des Arbeitskreises Blut am \\ 10.11.2020 wurde folgendes Votum (V 48) \\ verabschiedet
}

Ergänzt wird das Votum durch den Anhang $\mathrm{F}$, in dem die Kriterien für die Bewertung eines Verdachts einer Infektionsübertragung durch Blutprodukte nach Abschluss des RVV ausgeführt werden.

Dieses Votum ersetzt das Votum 47 des Arbeitskreises Blut.

\section{A Verfahren zur Rückverfolgung}

\section{A 1 Zweck}

Durch das Verfahren zur Rückverfolgung sollen Infektionsübertragungen durch noch nicht angewendete Blutprodukte verhindert und eventuell stattgefundene Infektionen durch Blutprodukte erkannt werden. Die spendende Person soll bei bestätigtem Infektionsverdacht eingehend aufgeklärt und beraten werden, insbesondere über Therapiemöglichkeiten.

\section{A 2 Anwendung}

Das Verfahren zur Rückverfolgung kommt zur Anwendung, wenn

a) bei einer spendenden Person eine Infektion mit HIV, mit Hepatitisviren, WNV oder anderen Erregern, die zu schwerwiegenden Krankheitsverläufen führen können, festgestellt wurde;

b) bei einer mit Blutprodukten behandelten Person eine Infektion, insbesondere mit HIV, HBV, HCV, HEV oder WNV, festgestellt wird und der begründete Verdacht besteht, dass sie durch Blutprodukte verursacht wurde; c) nachträglich festgestellt wird, dass die zur Freigabe genutzten Testergebnisse für Infektionsmarker falsch-negativ waren, deshalb zu falschen Ergebnissen geführt haben könnten und der begründete Verdacht besteht, dass das freigegebene Blutprodukt Infektionserreger übertragen könnte.

\section{A 3 Voraussetzungen}

A 3.1 Die Einrichtungen der Krankenversorgung haben ein Qualitätssicherungssystem etabliert, das die Einhaltung der Dokumentations- und Unterrichtungspflichten gemäß \$\$14, 16 und 19 TFG garantiert.

\begin{tabular}{|ll}
\hline \multicolumn{2}{|l}{ Abkürzungen } \\
\hline$A M G$ & Arzneimittelgesetz \\
\hline$H B V$ & Hepatitis-B-Virus \\
\hline$H B C$ & Hepatitis-B-Core-Antigen \\
\hline$H B s A g$ & Hepatitis-B-Oberflächenantigen \\
\hline$H C V$ & Hepatitis-C-Virus \\
\hline$H E V$ & Hepatitis-E-Virus \\
\hline$H I V$ & humanes Immunschwächevirus \\
\hline NAT & Nukleinsäure-Amplifikations- \\
\hline Technik \\
\hline NUP & Nachuntersuchungsproben \\
\hline LoD & Limit of Detection \\
\hline$T F G$ & Transfusionsgesetz \\
\hline WNV & West-Nil-Virus \\
\hline
\end{tabular}


A 3.2 Blutspendeeinrichtungen haben ein Vigilanzsystem etabliert, das die Einhaltung der Dokumentations- und Meldepflichten gemäß \$63i AMG und $\$ 22$ TFG sowie die Durchführung eines Verfahrens zur Rückverfolgung gemäß \$19 TFG garantiert.

A 3.3 Blutspendeeinrichtungen erstellen Nachuntersuchungsproben (NUP) von jeder Spende.

a) Anlässlich jeder Spende zur Herstellung von Blutkomponenten zur allogenen Transfusion sollen mindestens 1,5 $\mathrm{ml}$ Serum/Plasma abgetrennt und bei $\leq-30{ }^{\circ} \mathrm{C}$ als NUP aufbewahrt werden. Diese NUP sollen in mindestens 2 Aliquoten in verschließbaren Behältnissen gelagert sein. Das Volumen der NUP muss so gewählt sein, dass eine Nachtestung mittels NAT sichergestellt ist.

b) NUP sind mindestens 3 Jahre bzw. bis mindestens 1 Jahr über die Haltbarkeitsdauer des aus der Spende hergestellten Plasmas zur Transfusion aufzubewahren.

c) Die Analyse von NUP erfolgt mittels Einzelspenden-NAT (ID-NAT) auf den die Rückverfolgung auslösenden Erreger (analytische Sensitivität gemäß Anhang A2, B2, C2, D bzw. E).

\section{NUP dienen}

- der Aufklärung potenzieller Infektiosität von (Vor-)Spenden im Rahmen der Rückverfolgung;

- der Abklärung eventueller retrospektiv bekannt gewordener Probleme bei der Testung;

- im Falle des Nachweises eines Virusgenoms der Identitätsprüfung von Genomsequenzen bei der spendenden Person und der mit Blutprodukten behandelten Person;

- der Untersuchung auf Krankheitserreger außerhalb der Routinediagnostik im Rahmen der Rückverfolgung.

\section{A 4 Besonderheiten}

Ergeben sich nachträglich Hinweise, dass die zur Freigabe einer Spende von Blut oder Bestandteilen aus Blut vorgenommenen Testungen auf Virusmarker möglicherweise falsch-negativ waren, ist eine
Risikobewertung ggf. mit der zuständigen Behörde durchzuführen. Entsprechend dem Ergebnis sind geeignete Sofortmaßnahmen einzuleiten.

\section{B Infektionsverdacht ausgehend von der spendenden Person}

\section{B 1 Verdacht einer Infektion bei der spendenden Person}

B 1.1 Der Verdacht einer Infektion bei der spendenden Person ergibt sich aus positiven bzw. reaktiven Ergebnissen an Untersuchungsproben, die anlässlich der Spende oder zur Freigabe von Plasma zur Transfusion aus der Quarantänelagerung abgenommen wurden.

Ergibt sich der Infektionsverdacht aus Ergebnissen von NUP oder aus Ergebnissen von speziell angeforderten Untersuchungsproben z.B. infolge anamnestischer Angaben von Symptomen, einer Erkrankung oder von Nachuntersuchungen bei nachträglichen Zweifeln an der Validität eines verwendeten Testsystems, ist analog B $1.2 \mathrm{zu}$ verfahren.

B 1.2 Ergibt sich bei einer spendenden Person der Verdacht einer Infektion, ist hinsichtlich der Sperrung von Spende bzw. spendender Person gemäß Anhang A1, B1, C1, D bzw. E zu verfahren.

\section{B 2 Ausschluss bzw. Bestätigung des Verdachts einer Infektion bei der spendenden Person (1. Blutprobe)}

B 2.1 Der initiale Befund im Screening und damit die Infektion bei der spendenden Person ist bestätigt,

- HIV, HBV, HCV: wenn die zweifache Nachtestung mittels ID-NAT oder die Auflösung des NAT-Minipools oder die zusätzlich durchgeführten Untersuchungen gemäß Anhang A2, B2, bzw. C2 positiv ausfallen.

Wird vermutet, dass positive Befunde aus der HBsAg-Bestätigungstestung auf eine Impfung zurückzuführen sind, so ist die Impfanamnese anhand des Impfausweises oder vergleichbarer Dokumentation zu sichern. Die Beurteilung, ob die reaktiven Ergebnisse in der ersten Bestätigungstes- tung (Anhang B2) auf eine kürzlich erfolgte HBV-Impfung zurückzuführen sind und kein Infektionsverdacht besteht, erfolgt im Einzelfall.

- HEV: wenn die zweifache Nachtestung mittels ID-NAT oder die Auflösung des NAT-Minipools gemäß Anhang D positiv ausfällt.

- WNV: wenn die zweifache Nachtestung mittels ID-NAT oder die Auflösung des NAT-Minipools gemäß Anhang E positiv ausfällt.

In Abhängigkeit von der Spezifität der verwendeten Screening-NAT ist zur Sicherung der WNV-Infektion eine Kreuzreaktivität mit anderen Flaviviren, hier der Serogruppe der japanischen Enzephalitis, durch weitere differenzialdiagnostische Untersuchungen auszuschließen.

Diese Untersuchungen können grundsätzlich abschließend aus der initialen Untersuchungsprobe durchgeführt werden.

B 2.2 Ein im Screening erhaltenes positives und/oder reaktives Testergebnis wird als nicht bestätigt eingestuft, wenn

- bei zweifacher Nachtestung des Screeningergebnisses mittels ID-NAT oder

- nach Auflösung des NAT-Minipools gemäß Anhang A1, B1, C1, D bzw. E oder

- nach den zusätzlich durchgeführten Testungen zur Abklärung wiederholt reaktiver Testergebnisse gemäß Anhang A2, B2 bzw. C2

nur negative oder nichtreaktive Ergebnisse erhalten werden.

\section{B 3 Ausschluss bzw. Bestätigung des Verdachts einer Infektion bei der spendenden Person (2. Blutprobe)}

B 3.1 Ist bei der Labordiagnostik zur Feststellung des Infektionsstatus gemäß Anhang A2 bzw. C2 das Ergebnis unbestimmt, so soll innerhalb von 7 bis 21 Tagen nach der ursprünglichen Blutabnahme eine zweite Blutprobe gewonnen werden. Eine Frist von wenigstens $7 \mathrm{Ta}$ gen ist einzuhalten, um eine beginnende Serokonversion deutlich werden zu lassen. Die Testungen an der zweiten Blutprobe 
sind gemäß Anhang A3 bzw. C3 durch die Spendeeinrichtung selbst oder im Auftrag der Spendeeinrichtung durch ein externes Labor durchzuführen.

B 3.2 Durch die Untersuchung der 2 . Blutprobe kann gemäß Anhang A3 bzw. C3 der Infektionsverdacht bestätigt oder ausgeschlossen werden. Ergibt sich erneut ein unbestimmtes Ergebnis, wird der Befund endgültig als unbestimmt gewertet und gemäß B 6.2 kann das RVV beendet werden und die unten folgenden Maßnahmen (B 4.5 - B 4.8) müssen nicht durchgeführt werden.

\section{B 4 Von der spendenden Person ausgehendes RVV}

B 4.1 Bei bestätigter Infektion oder unbestimmtem Ergebnis aus der ersten Blutprobe gemäß den Anhängen A2, B2, C2 bzw. D und bei positivem WNVScreeningergebnis gemäß Anhang $\mathrm{E}$ ist ein RVV zur Aufklärung der potenziellen Infektiosität von vorhandenen oder schon verabreichten Blutprodukten aus Vorspenden durchzuführen.

Die endgültige bzw. zeitlich begrenzte Sperrung der spendenden Person richtet sich nach Anhang A1, B1, C1, D bzw. E. Die vorausgehenden Spenden sind unverzüglich nach B 4.2 bis B 4.4 zu ermitteln.

B 4.2 Der Betrachtungszeitraum für die Ermittlung des Stichtages beträgt 3 Jahre für HIV, HBV und $\mathrm{HCV}, 6$ Monate für HEV und 4 Wochen für WNV vor dem Entnahmedatum der Spende oder Blutprobe, deren Untersuchungsergebnis den Verdacht einer Infektion (siehe auch B 1.1) ausgelöst hat. Für WNV gilt zusätzlich, dass der Betrachtungszeitraum zur Ermittlung der Stichtagsspende nicht über den Zeitraum vor dem 1. Juni des jeweiligen Jahres erweitert werden muss [Bekanntmachung vom 18.03.2020 BAnz AT 04.06.2020 B6].

B 4.3 Für die Ermittlung von Vorspenden gilt als Stichtag der Entnahmetag, an dem das letzte Mal im Screening ein für den Erreger negatives Ergebnis erhoben wurde bzw. von dem kein Screeningtestergebnis vorliegt.
Das gilt analog für Blutentnahmen der spendenden Person, die in diesem Zeitraum in der Spendeeinrichtung auch unabhängig von Spenden durchgeführt wurden.

Es sind folgende Spenden zu identifizieren:

- HIV, HCV, HEV: Alle dem Stichtag 12 Wochen vorausgehenden Spenden.

- HBV: Alle dem Stichtag 16 Wochen vorausgehenden Spenden.

- WNV: Alle dem Stichtag 4 Wochen vorausgehenden Spenden.

B 4.4 Ergibt die Testung der NUP vom Stichtag ein positives Ergebnis in der ID-NAT und damit den Hinweis, dass die spendende Person schon zum Zeitpunkt der Probennahme infektiös gewesen sein kann, wird der Stichtag nach B 4.3 neu festgelegt und mit den Vorspenden innerhalb des Betrachtungszeitraums für den jeweiligen Erreger analog verfahren.

Bei negativem Ergebnis der NAT in der NUP der Stichtagsspende gilt B 6.1. Kann das RVV gemäß B 6.1 beendet werden, so müssen die folgenden Maßnahmen (B 4.5 - B 4.8) nicht durchgeführt werden.

B 4.5 Von nach B 4.3 und B 4.4 identifizierten Blutentnahmen oder Spenden werden die früher erhobenen Untersuchungsergebnisse anhand der Dokumentation überprüft. Alles in der Blutspendeeinrichtung noch vorhandene Blut bzw. alle noch vorhandenen Bestandteile aus Blut werden ausgesondert und sichergestellt.

Als Ausnahme bei bestätigtem Verdacht auf eine Infektion der spendenden Person mit HEV oder positivem Screeningergebnis für WNV gilt: Wird die NUP einer Stichtagsspende ID-NAT-negativ getestet, so kann das daraus hergestellte Quarantäneplasma freigegeben werden, sofern alle anderen Freigabekriterien erfüllt sind.

B 4.6 Einrichtungen der Krankenversorgung/ärztliche Personen, an die Blutprodukte aus gemäß B 4.3 und B 4.4 identifizierten Spenden geliefert wurden, werden unverzüglich benachrichtigt, soweit Blutprodukte noch in der Laufzeit sind. Sie sondern noch vorhandene Blutprodukte aus und stellen diese sicher.
B 4.7 Wurde Plasma aus gemäß B 4.3 und B 4.4 identifizierten Spenden an ein Plasma verarbeitendes Unternehmen geliefert, wird das Plasma verarbeitende Unternehmen vereinbarungsgemäß über identifizierte Vorspenden informiert.

B 4.8 Im Fall von ID-NAT-positiv getesteten NUP oder wenn eine Untersuchung der NUP von nach B 4.3 und B 4.4 ermittelten Vorspenden nicht möglich ist, wird das RVV mit den transfundierenden Einrichtungen der Krankenversorgung fortgeführt.

B 5 Fortführung des von der spendenden Person ausgehenden RVV mit den Einrichtungen der Krankenversorgung

B 5.1 Die Einrichtungen der Krankenversorgung/ärztlichen Personen ermitteln die Personen, die Blutprodukte aus nach B 4.3 und B 4.4 identifizierten Spenden erhalten haben.

Sie werden seitens der Blutspendeeinrichtungen unverzüglich über positive Ergebnisse aus NUP der identifizierten Spenden unterrichtet.

Sofern eine Untersuchung der NUP nicht möglich war, so sind Empfänger von Blutprodukten aus der Stichtagsspende und aus den vorangegangenen Spenden im Zeitraum von

- für HIV, HCV: 12 Wochen,

- für HBV: 16 Wochen

zu ermitteln.

Für HEV und WNV gilt, dass Empfänger zu ermitteln sind, die Blutprodukte erhalten haben aus Spenden, die innerhalb von 12 Wochen (HEV) bzw. 4 Wochen (WNV) vor der erstmals im Screening positiven Spende abgenommen wurden.

Den Einrichtungen der Krankenversorgung wird die diagnostische Abklärung einer möglichen transfusionsbedingten Infektion gemäß den gültigen nationalen bzw. internationalen Leitlinien zur Diagnostik empfohlen.

Gemäß $\$ 19$ (1) Satz 6-8 TFG ist vor der Testung die schriftliche Einwilligung der behandelten Person seitens der Einrichtung der Krankenversorgung ein- 
zuholen, in deren Verantwortung die behandelte Person auch über den Infektionsverdacht zu unterrichten und eingehend zu beraten ist.

B 5.2 Ergibt die diagnostische Abklärung bei den Personen, die Blutprodukte erhalten haben, den begründeten Verdacht einer transfusionsbedingten Infektion, versucht die Spendeeinrichtung durch geeignete Untersuchungen (z.B. vergleichende Genomanalyse), die Kausalität abzuklären (Anhang F).

\section{B 6 Abschluss des von der spendenden Person ausgehenden RVV}

B 6.1 Das RVV kann auf Basis der Analyse der NUP (siehe auch B 4.3 und B 4.4) beendet werden

- für HIV, HCV, HEV bzw. WNV: sobald in der NUP der Spende vom Stichtag bzw. bei schrittweiser Testung ausgehend von der Stichtagsprobe in einer der Vorspenden ein negatives ID-NAT-Ergebnis für den jeweiligen Erreger vorliegt;

- für HBV: wenn alle NUP im nach B 4.3 und B 4.4 festgelegten Untersuchungszeitraum ein negatives ID-NAT-Ergebnis aufweisen. ${ }^{1}$

B 6.2 Das RVV kann beendet werden, sofern bei der Testung der zweiten Blutprobe gemäß Anhang A3 bzw. C3 negative bzw. erneut unbestimmte Ergebnisse erhalten werden.

B 6.3 Das RVV kann auf Basis der diagnostischen Abklärung beendet werden, sobald eine Bewertung des Kausalzusammenhangs der Infektion der spendenden und der mit Blutprodukten behandelten Person gemäß Anhang F erfolgt ist.

B 6.4 Wenn das von der spendenden Person ausgehende RVV gemäß B 5 mit den Einrichtungen der Krankenversorgung fortgeführt wurde, kann es beendet werden, wenn innerhalb von 8 Wochen keine

1 Für Plasma zur Fraktionierung gilt derzeit die $_{\text {„Guideline on plasma-derived medical }}$ products" (EMA/CHMP/706271/2010), d.h. 6 Monate.
Informationen über die Personen zur Verfügung gestellt wurden, die Blutprodukte erhalten haben aus

- einer in der NUP positiv getesteten Spende

oder

- aus Spenden im nach B 5.1 definierten Zeitraum, von denen eine Testung der NUP nicht möglich ist.

Die Möglichkeit eines von der empfangenden Person ausgehenden RVV bei nachträglich eingehenden Hinweisen, dass eine Infektionsübertragung stattgefunden haben könnte, bleibt unberührt.

\section{B 7 Unterrichtung der spendenden Person über den festgestellten Infektionsstatus}

B 7.1 Ergibt sich aus der Analyse der Untersuchungsproben (1. Blutprobe) gemäß Anhang A2, B2, C2, D ein bestätigt positives Ergebnis bzw. gemäß Anhang E ein positives Ergebnis, wird die spendende Person durch eine von der Spendeeinrichtung benannte ärztliche Person und/oder der von ihr angegebenen ärztlichen Person ihres Vertrauens unverzüglich informiert. Diese Information, Aufklärung und Beratung, insbesondere auch über Therapiemöglichkeiten, sind in jedem Einzelfall nach Art und Umfang festzulegen und zu dokumentieren.

B 7.2 Bei unbestimmten Untersuchungsergebnissen (siehe Anhang A2 bzw. C2) sollten die Information und Beratung der spendenden Person analog B 7.1 erst nach Vorliegen der Ergebnisse der 2. Blutprobe (siehe B 3) vorgenommen werden. Die Entscheidung für eine zeitweise oder dauerhafte Sperrung der spendenden Person obliegt der Spendeeinrichtung (siehe Anhang A1 bzw. C1).

B 7.3 Ergibt die HBV-Labordiagnostik bei der spendenden Person eine spezifische Anti-HBc-Reaktivität (siehe Anhang B2), erfolgen eine Information und Beratung der spendenden Person analog B 7.1.

B 7.4 Kann innerhalb von 5 Wochen nach dem Entnahmedatum der Spende der Infektionsstatus nicht sicher festgestellt werden, ist die spendende Person analog B 7.1 $\mathrm{zu}$ informieren und eine Beratungsmöglichkeit anzubieten.

\section{Infektionsverdacht ausgehend von der mit Blutprodukten behandelten Person}

\section{1 Verdacht einer Infektion \\ bei einer mit Blutprodukten \\ behandelten Person}

C 1.1 Eine Infektion bei einer mit Blutprodukten behandelten Person wird gemäß den gültigen nationalen bzw. internationalen Leitlinien ${ }^{2,3}$ zur Diagnostik nachgewiesen.

C 1.2 Der begründete Verdacht der Übertragung einer Infektion durch Blutprodukte ergibt sich bei einer mit Blutprodukten behandelten Person, wenn eine Infektion nachgewiesen ist und ernst zu nehmende Anhaltspunkte (z.B. vor Applikation bekannte negative Serologie-/NAT-Ergebnisse, Serokonversion, Virusnachweis mit oder ohne klinische Symptome in zeitlichem Zusammenhang zur Transfusion) bestehen, dass die Infektion durch verabreichte Blutprodukte übertragen wurde.

\section{2 RVV bei Verdacht auf eine transfusionsbedingte virale Infektion}

C 2.1 Ergibt sich bei einer Person, die Blutprodukte erhalten hat, der Nachweis einer Infektion und daraus der begründete Verdacht einer Übertragung durch Blutprodukte, wird von der behandelnden ärztlichen Person/Einrichtung zur Krankenversorgung gemäß $\$ 19$ (2) in Verbindung mit $\$ 16$ TFG unverzüglich ein RVV eingeleitet.

C 2.2 Von der behandelnden ärztlichen Person/Einrichtung der Krankenversorgung werden alle der Person verabreich-

\footnotetext{
2 AWMF; Arbeitsgemeinschaft der Wissenschaftlichen Medizinischen Fachgesellschaften e.V. (https://www.awmf.org/leitlinien/aktuelleleitlinien.html).

3 Empfehlungen der Europäischen Vereinigung für das Studium der Leber (EASL, https://easl. eu/wp-content/uploads/2018/10/EASL-CPGhepatitis-E-virus-infection.pdf).
} 
ten Blutprodukte und die zugeordneten Blutspendeeinrichtungen ermittelt.

C2.3 Die betroffenen Blutspendeeinrichtungen werden unverzüglich über den Infektionsverdacht und die verabreichten Blutprodukte unterrichtet. Ihnen wird der schriftliche Befund der Infektionsdiagnostik der behandelten Person übermittelt.

\section{3 Fortführung des von mit Blutprodukten behandelten Personen ausgehenden RVV in den Blutspendeeinrichtungen als verantwortliche pharmazeutische Unternehmen}

C 3.1 Die Blutspendeeinrichtung, die die verabreichten Blutprodukte hergestellt hat, veranlasst die Identifikation der zugehörigen spendenden Personen.

C 3.2 Eventuell vorhandene Blutprodukte aus Spenden der implizierten spendenden Person werden identifiziert und sichergestellt, außer wenn die Kriterien unter C 3.4 erfüllt sind oder die Ausnahme für Quarantäneplasma nach B 4.5 zutrifft.

C 3.3 Von identifizierten Spenden werden die früher erhobenen Laborbefunde anhand der Dokumentation überprüft.

C 3.4 Die Blutspendeeinrichtung ermittelt, ob spätere Untersuchungen an der/ den spendenden Person(en) eine entsprechende Infektion ausschließen oder unwahrscheinlich machen:

- Falls die spendende Person 12 Wochen oder später nach der Spende im Screening Anti-HIV nicht reaktiv, HIV-1-NAT-negativ, Anti-HCV nicht reaktiv und HCV-NAT-negativ war, ist die verdächtige Spende als nicht infektiös hinsichtlich HIV und HCV zu werten.

- Falls die spendende Person 16 Wochen oder später im Screening Anti$\mathrm{HBc}$ und $\mathrm{HBsAg}$ nicht reaktiv und gegebenenfalls HBV-NAT-negativ war, ist die verdächtigte Spende als nicht infektiös hinsichtlich HBV zu werten.
Für HEV und WNV nicht anwendbar, da eine NAT-Untersuchung einer späteren Spende keine sichere Aussage hinsichtlich der Infektiosität zum Stichtag erlaubt.

C 3.5 Liegen keine zur Abklärung beitragenden Untersuchungsergebnisse vor, wird die spendende Person unverzüglich zu einer diagnostischen Abklärung aufgefordert. Die Blutabnahme erfolgt so bald wie möglich. Liegt die implizierte Spende vom Zeitpunkt der neuerlichen Probennahme weniger als

- 12 Wochen bei HIV,

- 12 Wochen bei HCV,

- 16 Wochen bei HBV

zurück, muss zusätzlich zu dieser Probe eine weitere Blutprobe zu einem Zeitpunkt 12 Wochen bei HIV- und HCV-Infektion und 16 Wochen bei HBV-Infektion nach der implizierten Spende entnommen werden.

Für HEV und WNV nicht anwendbar, da eine spätere NAT-Untersuchung keine sichere Aussage hinsichtlich der Infektiosität zum Stichtag erlaubt.

C 3.6 Ist eine Infektion nach C 3.4 nicht ausgeschlossen und eine zweite Blutprobe nach C 3.5 nicht verfügbar, werden vorhandene NUP der identifizierten Spenden der verabreichten Blutprodukte auf den die Rückverfolgung auslösenden Erreger mittels ID-NAT untersucht.

C 3.7 Wird eine spendende Person identifiziert, bei der der Verdacht einer Infektion besteht bzw. zum Zeitpunkt der implizierten Spende bestand, muss ein von der spendenden Person ausgehendes RVV gemäß Abschnitt A durchgeführt werden.

C 3.8 Ist eine diagnostische Abklärung bei der spendenden Person nicht möglich, wird das von der spendenden Person ausgehende RVV dennoch eingeleitet.

C 3.9 Die Blutspendeeinrichtung unterrichtet die verantwortliche ärztliche Person/Einrichtung der Krankenversorgung über das Ergebnis des fortgeführten RVV, die ihrerseits die Person, die Blutprodukte erhalten hat, gemäß $\$ 19$ (1) Satz 6-8 TFG sachgerecht unterrichtet und eingehend berät.

\section{4 Abschluss des von der} behandelten Person ausgehenden RVV

Wird bei einer mit Blutprodukten behandelten Person eine Infektion nachgewiesen und besteht der begründete Verdacht, dass es sich um eine transfusionsbedingte Infektion handelt, so ist die Ursache zu untersuchen und zu bewerten (siehe auch $\$ 63 i(2)$ AMG). Der Vergleich der Virusgenomsequenzen aus dem Blut der spendenden Person und dem Blut der mit Blutprodukten behandelten Person kann die Ursächlichkeit der verabreichten Blutprodukte belegen oder ggf. ausschließen (Anhang F).

\section{Meldesysteme und Meldeverpflichtungen bei RVV}

D 1 Die Blutspendeeinrichtung unterhält ein Meldesystem, das bei bestätigter Infektion oder unbestimmtem Ergebnis gemäß der Anhänge A2, B2, C2, D bzw. E die unverzügliche Benachrichtigung der verantwortlichen ärztlichen Person/Einrichtung der Krankenversorgung (B 4.6) sicherstellt. Zum gleichen Zweck ist ein Meldesystem zur gegenseitigen Unterrichtung zwischen der Spendeeinrichtung und dem Plasma verarbeitenden Unternehmen einzurichten (B 4.7).

D 2 Ergibt sich bei einer mit Blutprodukten behandelten Person der begründete Verdacht einer transfusionsbedingten Infektion (C 1.2), bestehen die Unterrichtungspflichten nach $\$ 16$ TFG. Ebenso sind die Dokumentations- und Anzeigepflichten, die sich aus dem AMG ergeben, zu beachten (vgl. z. B. \$63i Absatz 2 AMG, Meldung von schwerwiegenden unerwünschten Reaktionen an die zuständige Bundesoberbehörde innerhalb von $15 \mathrm{Ta}$ gen). Hierzu werden Meldeformulare von der zuständigen Bundesoberbehörde zur Verfügung gestellt. Die Meldungen an die Arzneimittelkommission der deutschen Ärzteschaft bleiben unberührt.

D3 Die unverzügliche Meldung der Einleitung eines RVV an die zuständigen Behörden regelt sich nach $\$ 19$ (1) TFG. Für die von der spendenden Person ausgehenden RVV stehen eine Erläuterung so- 
wie für diese Meldung empfohlene Meldebögen der Zentralstelle der Länder für Gesundheitsschutz (ZLG) und des PaulEhrlich-Instituts (PEI) im Internet auf der Homepage des PEI zum Download bereit. Die Meldungen gemäß $\$ 22$ TFG bleiben unberührt.

\section{Glossar}

Analytische Sensitivität: in diesem Votum gleichzusetzen mit Nachweisgrenze für die NAT-Tests. Nach den CTS (Common Technical Specifications) die Konzentration, bei der $95 \%$ der Ansätze reaktiv sind.

Blutprodukte (Begriff des Transfusionsgesetzes): Blutzubereitungen im Sinne des $\S 4$ Abs. 2 des Arzneimittelgesetzes, Sera aus menschlichem Blut im Sinne des $\S 4$ Abs. 3 des Arzneimittelgesetzes und Blutbestandteile, die zur Herstellung von Wirkstoffen oder Arzneimitteln bestimmt sind.

Empfangende Person: eine Person, auf die Blutprodukte übertragen worden sind.

Nachuntersuchungsproben (NUP): Anlässlich einer Spende von Blut oder Bestandteilen aus Blut aufbewahrte Untersuchungsproben einer spendenden Person, die im Falle eines RVV die Nachuntersuchung der Ausgangsspende auf Infektionsmarker ermöglichen.

Reaktiv: serologisch nicht negativ (Messwert $>$ testspezifischer (ut-off)

Positiv: Genomnachweis (NAT)

Negativ: serologisch nicht reaktiv bzw. Genom (NAT) nicht nachweisbar

Spende: Die Spende ist die bei Menschen entnommene Menge an Blut oder Blutbestandteilen, die Wirkstoff oder Arzneimittel ist oder zur Herstellung von Wirkstoffen oder Arzneimitteln und anderen Produkten zur Anwendung beim Menschen bestimmt ist.

Spendeeinrichtung: eine Einrichtung, die Spenden entnimmt oder deren Tätigkeit auf die Entnahme von Spenden und, soweit diese zur Anwendung bestimmt sind, auf deren Testung, Verarbeitung, Lagerung und das Inverkehrbringen von Blutprodukten gerichtet ist.

\section{Für den Arbeitskreis Blut}

Dr. R. Offergeld, Vorsitzende 


\section{Anhang A1: HIV}

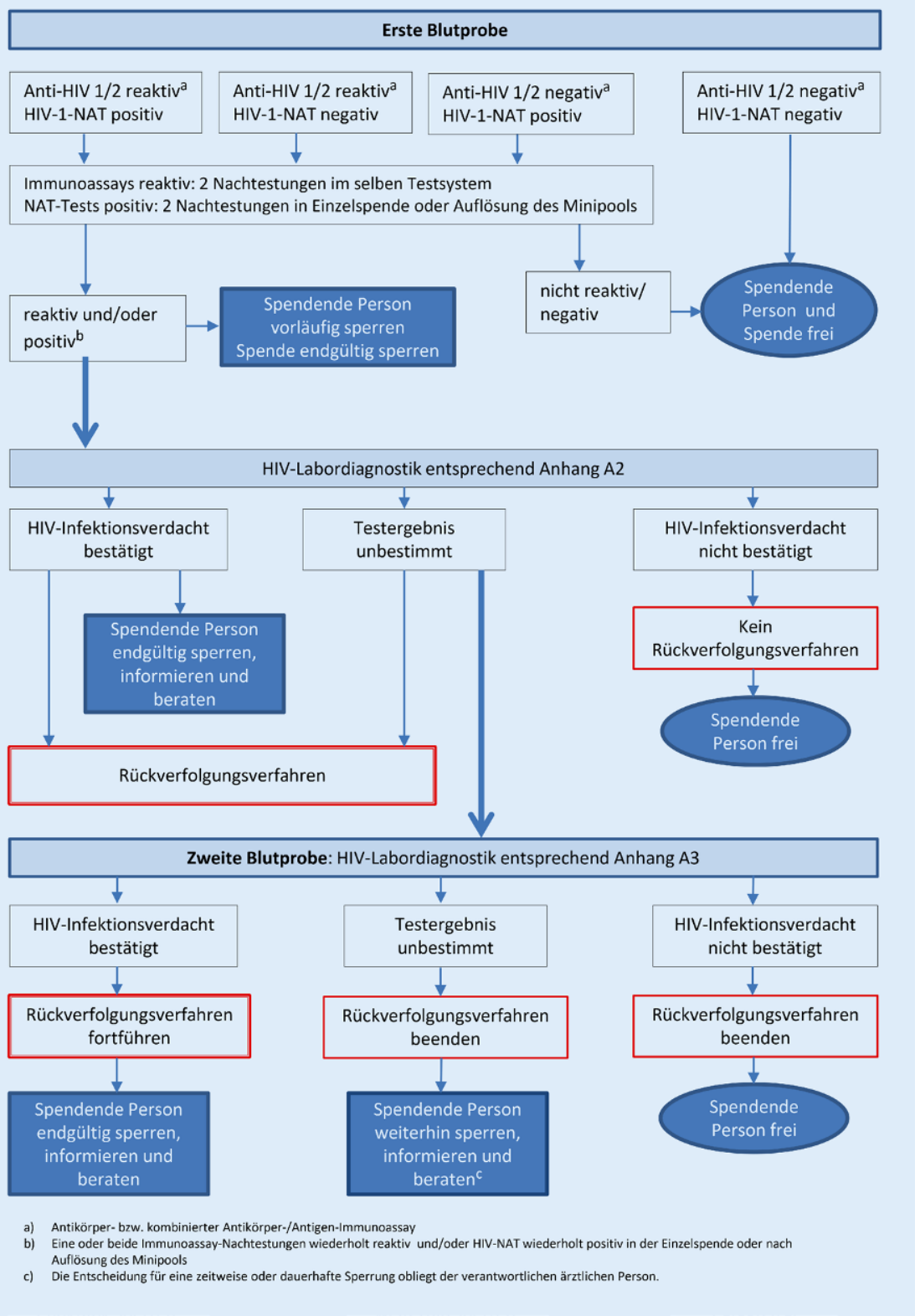




\section{Anhang A2: HIV}

Ergebnisse der gemäß Anhang A1

an der ersten Blutprobe

durchgeführten Screeningtests:

HIV 1/2-Immunoassay ${ }^{a}$, HIV-1-NAT

Humanes Immundefizienz Virus (HIV)

Erste Blutprobe: Labordiagnostik zur Feststellung des Infektionsstatus Einzelspende oder nach Auflösung des Minipools,

unabhängig vom Ergebnis der

Immunoassays

Anti-HIV $1 / 2^{\mathrm{a}}$ wiederholt reaktiv HIV-1-NAT negativ

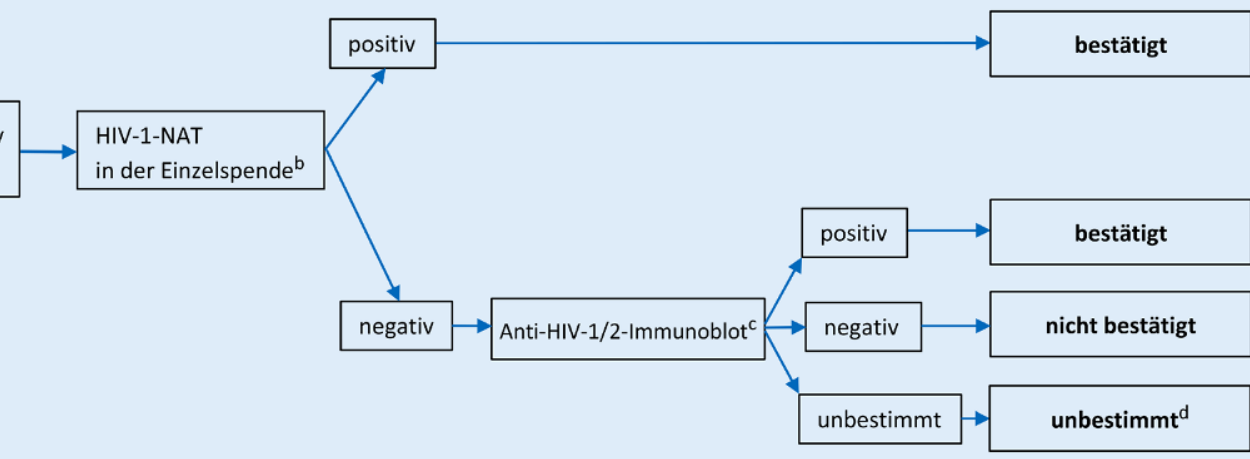

a) Antikörper-bzw. kombinierter Antikörper-/Antigentest

b) Analytische Sensitivität der Dual-target HIV-1 NAT bezogen auf die Einzelspende: $<100 \mathrm{IU} / \mathrm{ml}$

c) Getrennte HIV-1- und HIV-2-Immunoblots sind ebenfalls anwendbar. In diesem Fall muss mindestens einer der beiden Blots positiv ausfallen, um den Infektionsverdacht zu bestätigen.

d) Der Infektionsverdacht ist an einer zweiten Blutprobe nach Anhang A3 abzuklären. 


\section{Anhang A3: HIV}

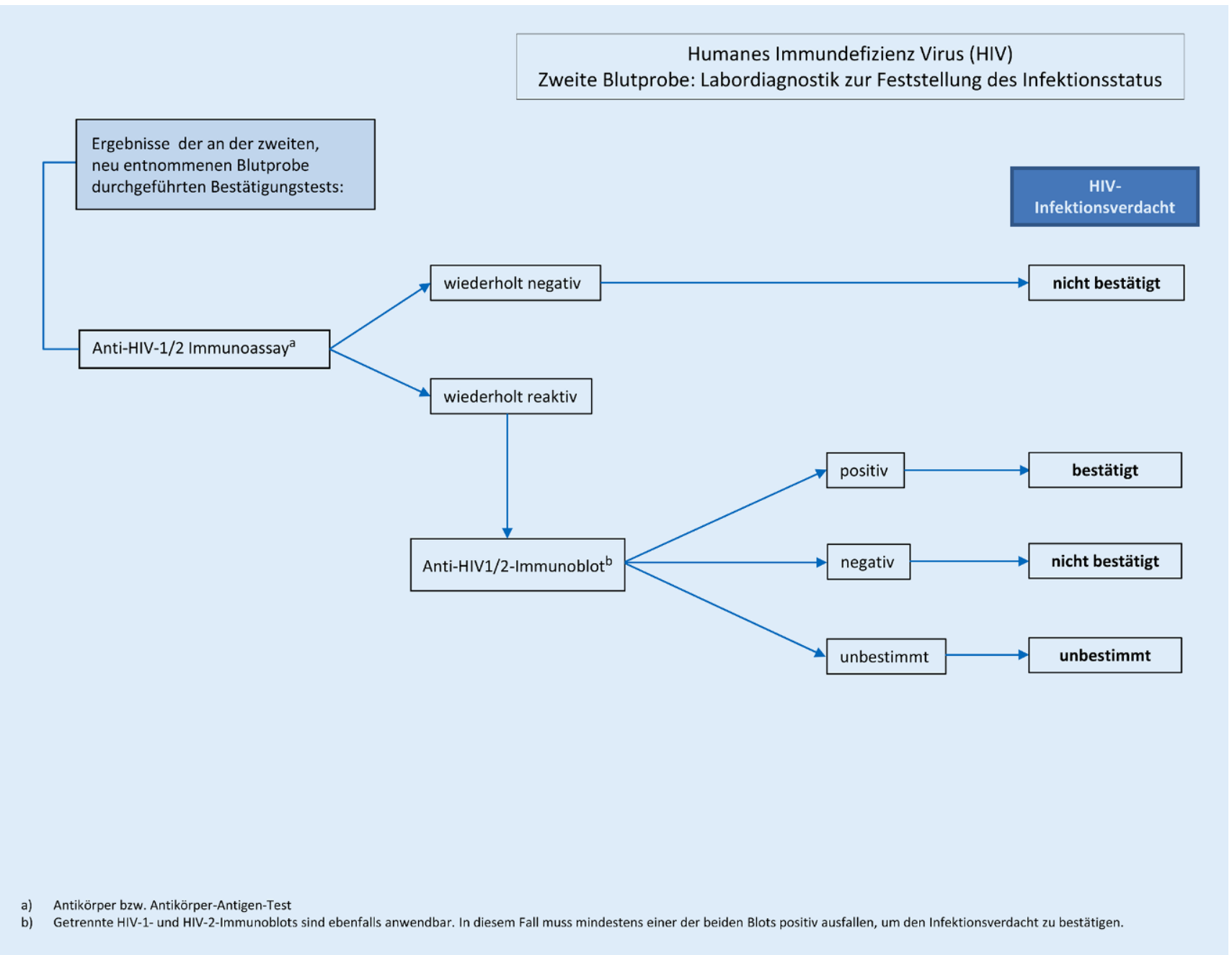




\section{Anhang B1: HBV}

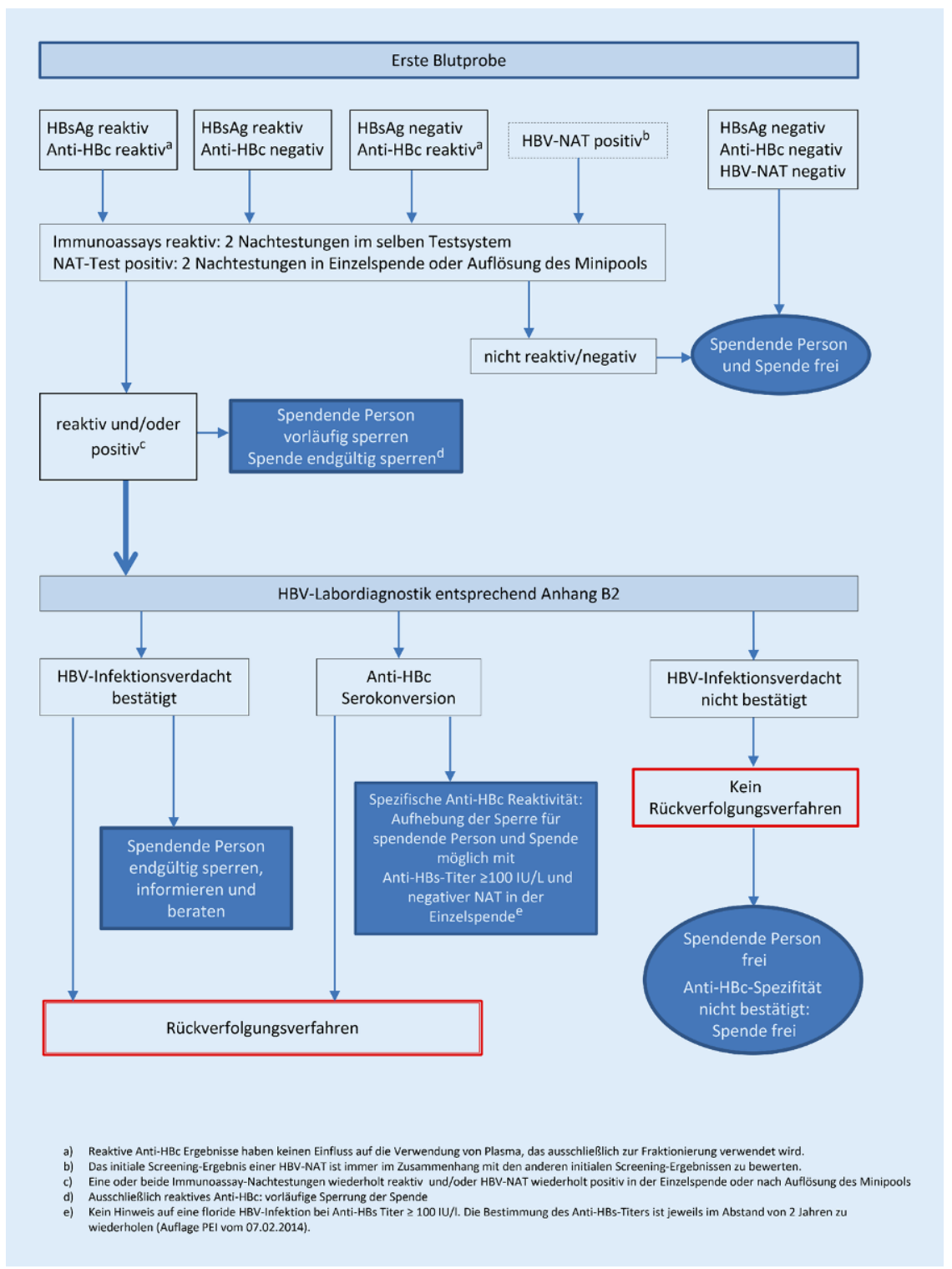




\section{Anhang B2: HBV}

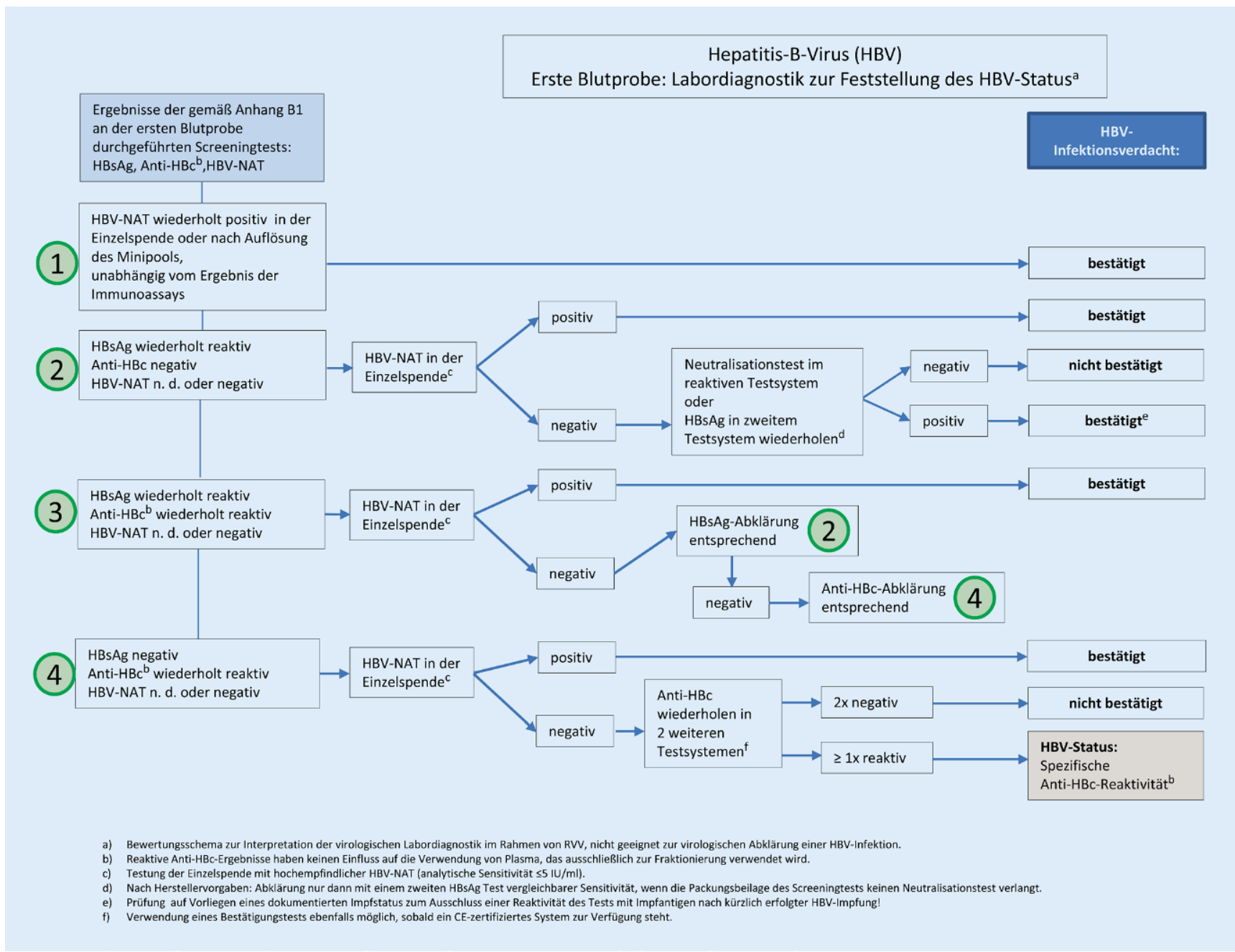




\section{Anhang C1: HCV}

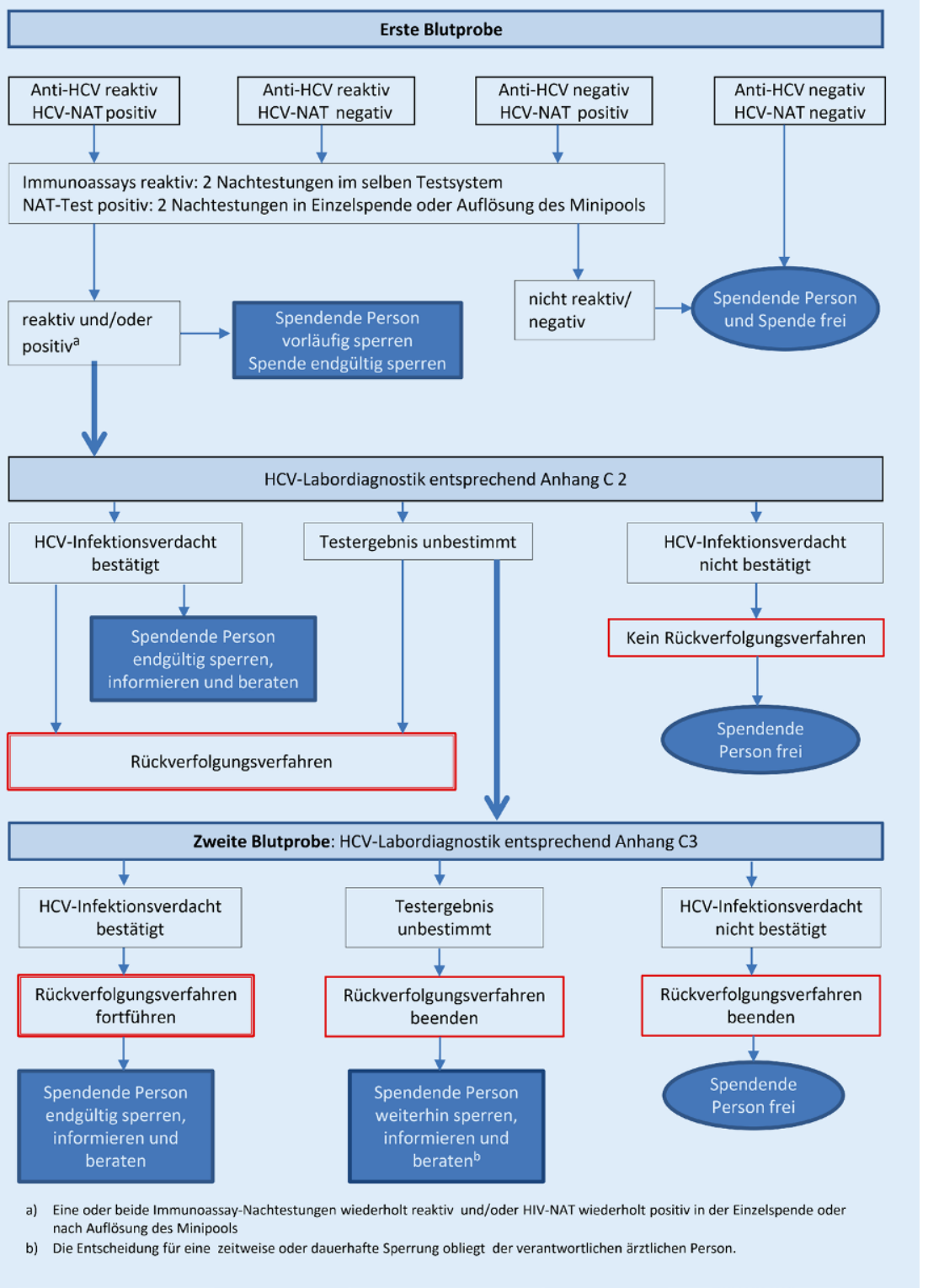




\section{Anhang C2: HCV}

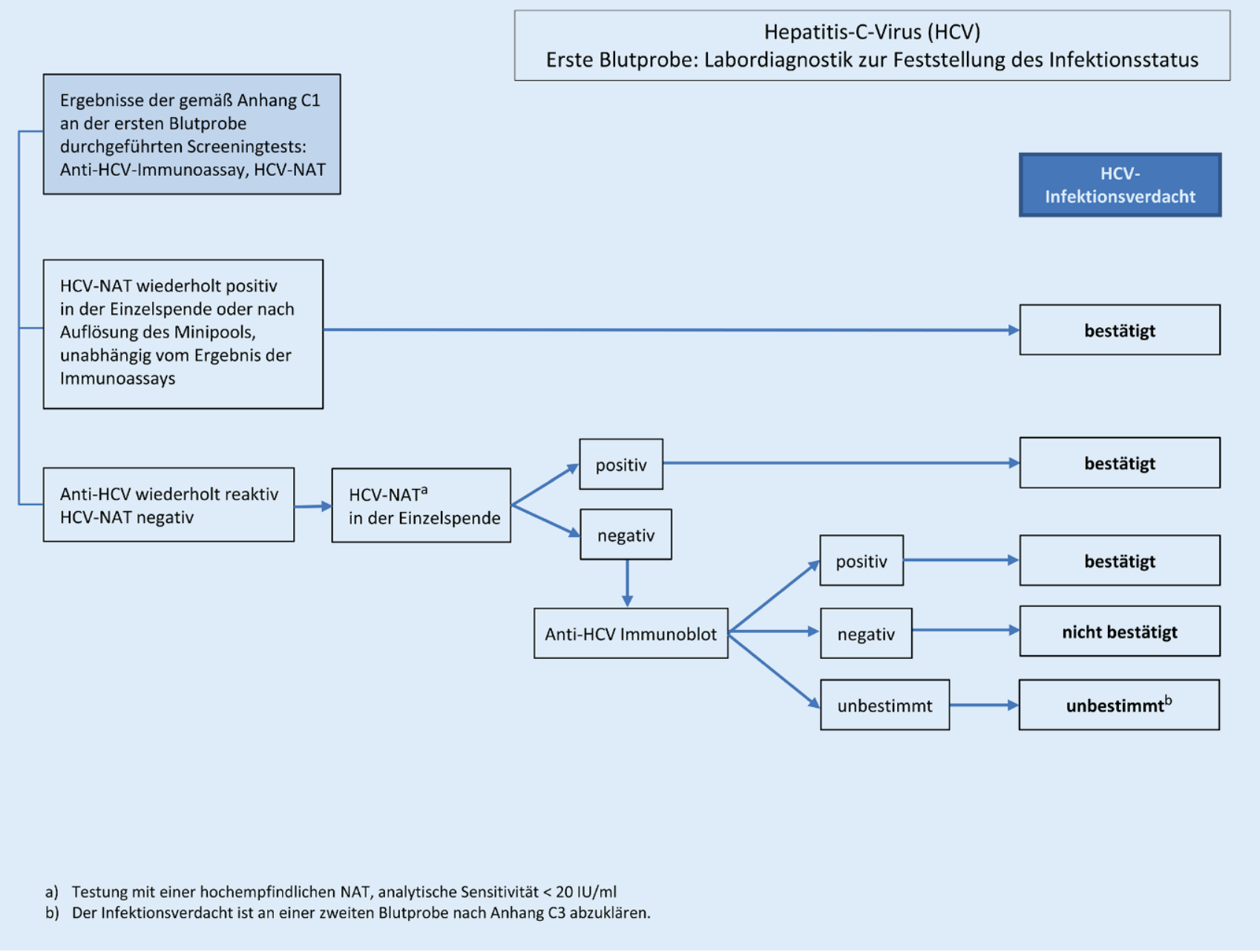




\section{Anhang C3: HCV}

Hepatitis-C-Virus (HCV)

Zweite Blutprobe: Labordiagnostik zur Feststellung des Infektionsstatus

Ergebnisse der an der zweiten,

neu entnommenen Blutprobe

durchgeführten Bestätigungstests:

nicht bestätigt

Anti-HCV Immunoassay a

wiederholt reaktiv

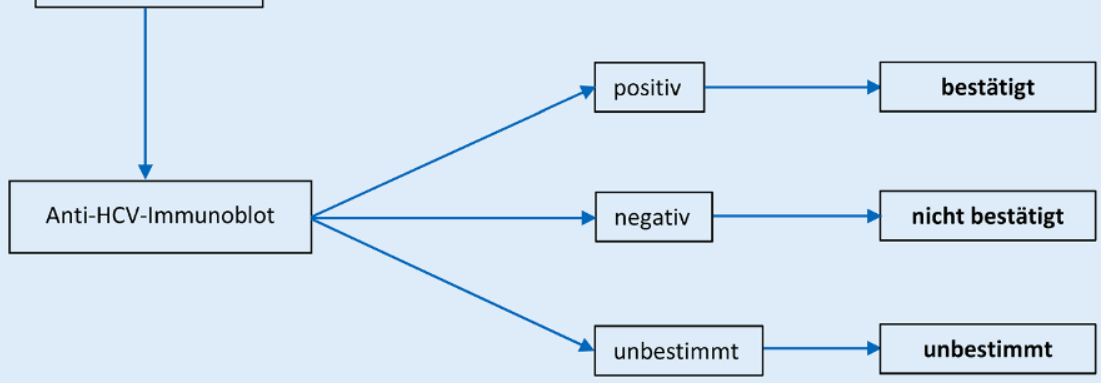

a) Antikörper-bzw. Antikörper-Antigen-Test 


\section{Anhang D: HEV}

Erste Blutprobe

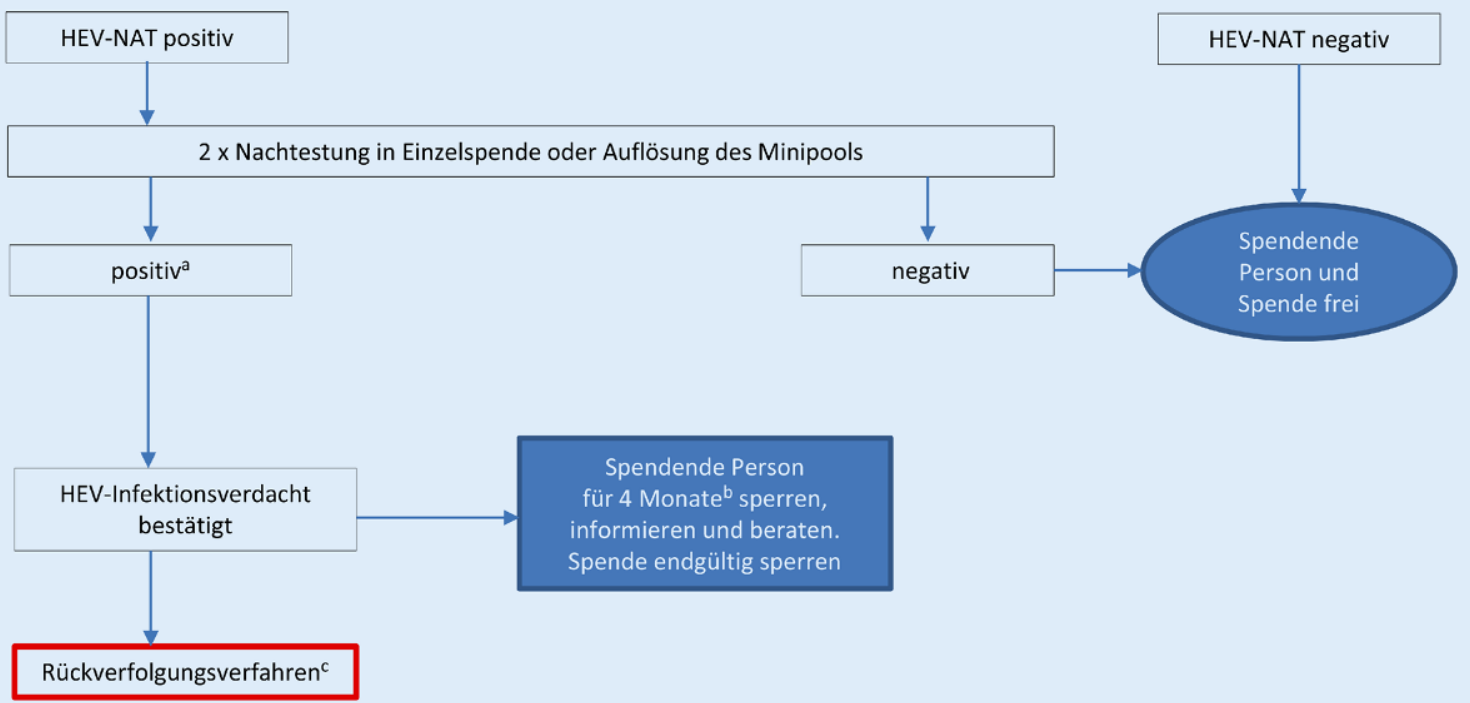

a) HEV-NAT wiederholt positiv in der Einzelspende oder nach Auflösung des Minipools

b) Wiederzulassung zur Spende $\geq 4$ Wochen nach HEV-NAT positiver Spende ist möglich bei negativem Ergebnis einer HEV-NAT in der Einzelspende mit einer analytischen Sensitivität von mindestens $50 \mathrm{IU} / \mathrm{ml}$.

c) Für die Testung in der NUP ist eine Mindestsensitivität von $50 \mathrm{IU} / \mathrm{ml}$ erforderlich. 


\section{Anhang E: WNV}

\section{Erste Blutprobe}

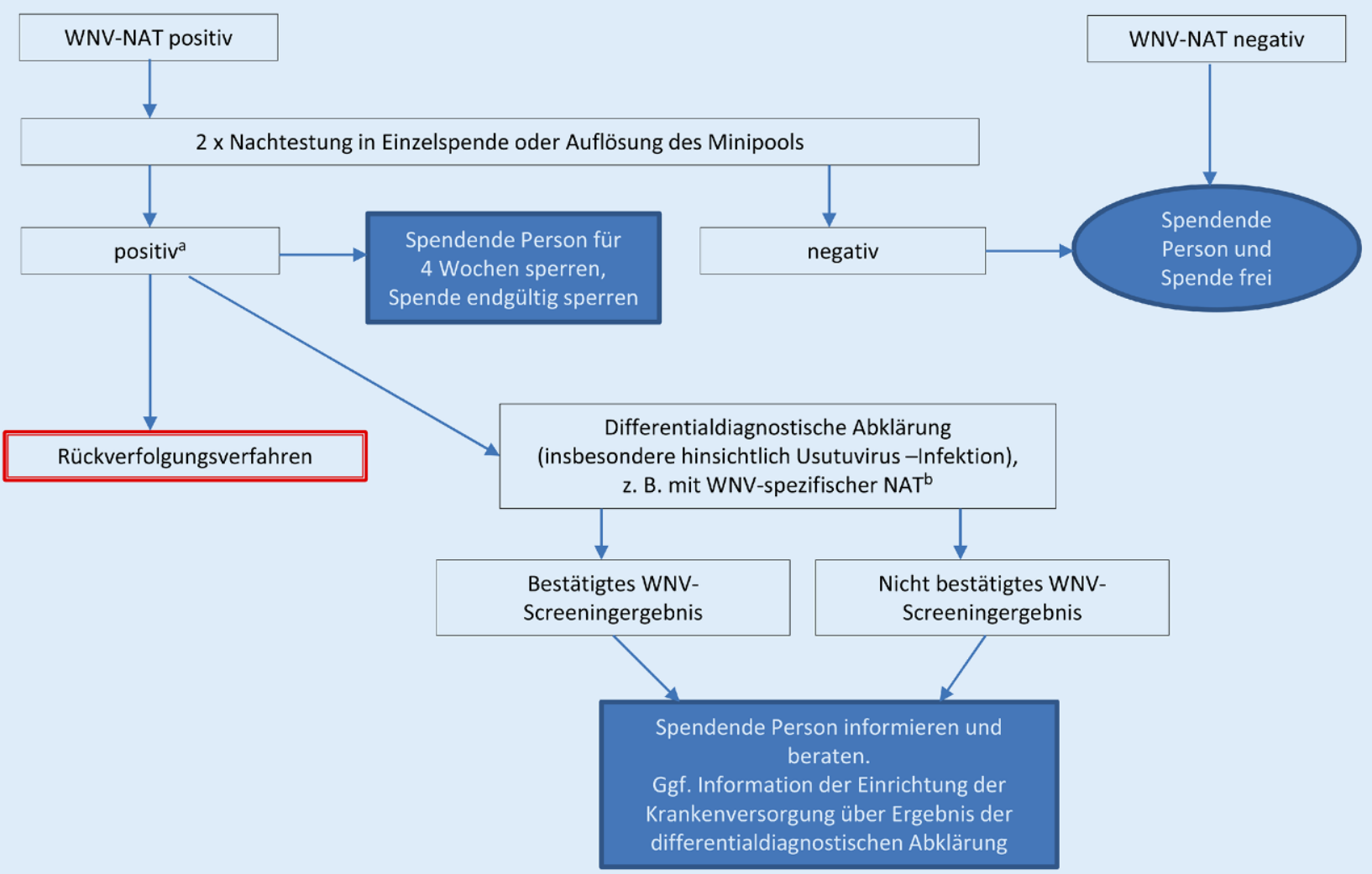

a) WNV-NAT wiederholt positiv in der Einzelspende oder nach Auflösung des Minipools, dies entspricht aufgrund der möglichen Kreuzreaktivität der Testverfahren noch nicht einer gesicherten WNV-Infektion nach Falldefinition gemäß IfSG

b) analytische Mindestsensitivität der WNV-NAT: $\leq 100 \mathrm{Kopien} / \mathrm{ml}$, gilt auch für die NUP 


\section{Anhang F: Zuordnungsstufen für schwerwiegende unerwünschte Reaktionen gemäß Richtlinie 2005/61/EG'; adaptiert für die Bewertung des Verdachts einer Virusübertragung durch Blutprodukte}

\begin{tabular}{|c|c|}
\hline Bewertung & Zuordnungsstufen \\
\hline sicher & $\begin{array}{l}\text { Es steht eindeutig und zweifelsfrei fest, dass die unerwünschte Reaktion auf Blut oder Blutbestandteile zurückzuführen ist: } \\
\text { Die Infektionen in der spendenden und der Blutprodukte empfangenden Person sowie ein zeitlich plausibler Zusammenhang } \\
\text { mit der Transfusion und eine eindeutige phylogenetische Sequenzhomologie beweisen, dass das Blutprodukt die Infektion in der } \\
\text { empfangenden Person verursacht hat. }\end{array}$ \\
\hline wahrscheinlich & $\begin{array}{l}\text { Es liegen deutliche Anzeichen dafür vor, dass die unerwünschte Reaktion auf Blut oder Blutbestandteile zurückzuführen ist: } \\
\text { Der zeitlich passende Zusammenhang und zusätzliche anamnestische Erkenntnisse (Infektion in spendender und empfangender } \\
\text { Person, außer Transfusion keine Übertragungswege plausibel), sprechen dafür, dass das Blutprodukt die Infektionen der empfan- } \\
\text { genden Person verursacht hat. Eine vergleichende Sequenzanalyse liegt nicht vor. }\end{array}$ \\
\hline möglich & $\begin{array}{l}\text { Es steht nicht eindeutig fest, ob die unerwünschte Reaktion auf Blut oder Blutbestandteile oder auf andere Ursachen zurückzuführen } \\
\text { ist: } \\
\text { Trotz der Infektion in der spendenden Person und des zeitlichen Zusammenhangs von Transfusion und Infektion in der empfan- } \\
\text { genden Person gibt es medizinisch plausible alternative Erklärungsmöglichkeiten, die eine Infektion durch die transfundierten } \\
\text { Blutprodukte nur als eine von mehreren Möglichkeiten erscheinen lassen. Eine vergleichende Sequenzanalyse liegt nicht vor. }\end{array}$ \\
\hline unwahrscheinlich & $\begin{array}{l}\text { Es liegen deutliche Anzeichen dafür vor, dass die unerwünschte Reaktion auf andere Ursachen als die Gabe von Blut oder Blutbe- } \\
\text { standteile zurückzuführen ist: } \\
\text { Trotz nachgewiesener Infektion in der spendenden und empfangenden Person sprechen der unklare zeitliche Zusammenhang } \\
\text { mit der Transfusion, die vorliegenden anamnestischen Angaben und die fehlende relevante phylogenetische Sequenzhomologie } \\
\text { gegen die Transfusion als Ursache der Infektion. }\end{array}$ \\
\hline ausgeschlossen & $\begin{array}{l}\text { Es steht zweifelsfrei fest, dass die unerwünschte Reaktion auf andere Ursachen als die Gabe von Blut oder Blutbestandteile zurück- } \\
\text { zuführen ist: } \\
\text { Das transfundierte Blutprodukt kann als Ursache der Infektion in der empfangenden Person ausgeschlossen werden, sofern eine } \\
\text { der drei nachfolgend genannten Möglichkeiten zutrifft. } \\
\text { - keine Infektion in der spendenden Person } \\
\text { - Infektion in der spendenden Person, aber keine Infektion in der empfangenden Person in zeitlich plausiblem Zusammenhang } \\
\text { mit der Transfusion (z. B. Merkmale der Infektion im Empfänger bereits zum Zeitpunkt der Transfusion) } \\
\text { - Infektion in spendender und empfangender Person, zeitlich plausibler Zusammenhang mit der Transfusion, aber Sequenz- } \\
\text { analyse schließt Identität des Virus in spendender und empfangender Person aus (unterschiedliche Genotypen bzw. Sub- } \\
\text { typen). }\end{array}$ \\
\hline nicht bewertbar & $\begin{array}{l}\text { Die Daten reichen für eine Zuordnungsbewertung nicht aus: } \\
\text { Die Datenlage ist ungenügend, weil z. B. wegen unzureichenden Probenvolumens oder zu geringer Viruslast keine aussagefähi- } \\
\text { gen Daten erhoben werden können bzw. weil spendende oder empfangende Person nicht mehr verfügbar sind. }\end{array}$ \\
\hline
\end{tabular}

\footnotetext{
1 RICHTLINIE 2005/61/EG DER KOMMISSION vom 30. September 2005 zur Durchführung der Richtlinie 2002/98/EG des Europäischen Parlaments und des Rates in Bezug auf die Anforderungen an die Rückverfolgbarkeit und die Meldung ernster Zwischenfälle und ernster unerwünschter Reaktionen. Anhang II Teil B: Ernste unerwünschte Reaktionen - Zuordnungsstufen.
} 


\section{Anhang F: Ausschlusskriterien für den Zusammenhang einer Virusinfektion mit einer Transfusion}

Ursächlichkeit des Blutprodukts für Empfängerinfektion ausgeschlossen, wenn:

\begin{tabular}{|c|c|c|c|}
\hline & $\begin{array}{l}\text { Ursächlichkeit des Blutprodukts für Empfängerinfektion } \\
\text { ausgeschlossen, wenn: }\end{array}$ & $\begin{array}{l}\text { LoD der ID-NAT-Tests zum } \\
\text { Ausschluss der Spenderin- } \\
\text { fektion }\end{array}$ & $\begin{array}{l}\text { Zielregion für die Genom- } \\
\text { sequenzanalyse zum Ausschluss } \\
\text { der Virusidentität }\end{array}$ \\
\hline HIV & $\begin{array}{l}\text { Kein Nachweis von Anti-HIV oder HIV-Genom } 12 \text { Wochen nach } \\
\text { der Spende bzw. der Gabe von Blutprodukten bei spendender } \\
\text { und/oder empfangender Person } \\
\text { - Empfangende Person war bereits zum Zeitpunkt der Gabe von } \\
\text { Blutprodukten HIV-infiziert } \\
\text { - Genomsequenzanalyse schließt phylogenetische Identität aus } \\
\text { (z.B. unterschiedlicher Subtyp) }\end{array}$ & $\begin{array}{l}\mathrm{NAT} \leq 100 \mathrm{IU} / \mathrm{ml} \\
(\mathrm{HIV}-1 \mathrm{RNA})^{c}\end{array}$ & $\begin{array}{l}\text { Polymerasegen (reverse Tran- } \\
\text { skriptase, Polymerase, Integrase } \\
\text { analog der Resistenztestung) und } \\
\text { zusätzlich, falls es keine eindeutige } \\
\text { Aussage gibt, noch den V3 Loop } \\
\text { (analog der Korezeptoranalyse) }\end{array}$ \\
\hline HBV & $\begin{array}{l}\text { Kein Nachweis von HBsAg, Anti-HBc oder HBV-Genom } 16 \\
\text { Wochen nach der Spende bzw. der Gabe von Blutprodukten } \\
\text { bei spendender }{ }^{\mathrm{a}} \text { und/oder empfangender Person }{ }^{\mathrm{b}} \\
\text { - Empfangende Person war bereits zum Zeitpunkt der Gabe von } \\
\text { Blutprodukten HBV-infiziert } \\
\text { - Genomsequenzanalyse schließt phylogenetische Identität aus } \\
\text { (z.B. unterschiedlicher Genotyp) }\end{array}$ & $\leq 5 \mathrm{IU} / \mathrm{ml}$ & ORF für das S-/Pol-Gen \\
\hline $\mathrm{HCV}$ & $\begin{array}{l}\text { Kein Nachweis von Anti-HCV oder HCV-Genom } 12 \text { Wochen } \\
\text { nach der Spende bzw. der Gabe von Blutprodukten bei spen- } \\
\text { dendera und/oder empfangender Person }{ }^{\mathrm{b}} \\
\text { - Empfangende Person war bereits zum Zeitpunkt der Gabe von } \\
\text { Blutprodukten HCV-infiziert } \\
\text { - Genomsequenzanalyse schließt phylogenetische Identität aus } \\
\text { (z.B. unterschiedlicher Genotyp) }\end{array}$ & $\leq 20 \mathrm{IU} / \mathrm{ml}$ & HVR1-codierende Region \\
\hline HEV & $\begin{array}{l}\text { Kein Nachweis von HEV-Genom in der Nachuntersuchungs- } \\
\text { probe der verdächtigten Spende und/oder kein Nachweis von } \\
\text { HEV-Genom und/oder einer Serokonversion nach der Gabe } \\
\text { von Blutprodukten bei empfangender Person } \\
\text { - Empfangende Person war bereits zum Zeitpunkt der Gabe von } \\
\text { Blutprodukten HEV-infiziert } \\
\text { - Genomsequenzanalyse schließt phylogenetische Identität aus } \\
\text { (z.B. unterschiedlicher Genotyp) }\end{array}$ & $\leq 50 \mathrm{IU} / \mathrm{ml}$ & $\begin{array}{l}\text { ORF1-Gen oder eine hypervariable } \\
\text { Zielregion in ORF2 (z. B.: nt } 5885 \\
\text { bis } 6510 \text { der GenBank-Sequenz } \\
\text { NC001434) }\end{array}$ \\
\hline WNV & $\begin{array}{l}\text { Kein Nachweis von WNV-Genom in der Nachuntersuchungs- } \\
\text { probe der verdächtigten Spende und/oder kein Nachweis von } \\
\text { WNV-Genom nach der Gabe von Blutprodukten bei empfan- } \\
\text { gender Person } \\
\text { - Empfangende Person war bereits zum Zeitpunkt der Gabe von } \\
\text { Blutprodukten WNV-infiziert } \\
\text { - Genomsequenzanalyse schließt phylogenetische Identität aus } \\
\text { (z.B. unterschiedlicher Genotyp) }\end{array}$ & $\leq 100$ Kopien/ml & $\begin{array}{l}\text { Vorzugsweise Gesamtgenom, } \\
\text { mindestens NS5-Gen }\end{array}$ \\
\hline \multicolumn{4}{|c|}{$\begin{array}{l}\text { as. Anhänge A2, A3, B2, C2, C3, D } \\
\text { 'labordiagnostischer Nachweis entsprechend den AWMF-Leitlinien (HIV, HCV, HBV) bzw. Empfehlungen der Europäischen Vereinigung für das Studium der Leber (EASL, } \\
\text { https://easl.eu/wp-content/uploads/2018/10/EASL-CPG-hepatitis-E-virus-infection.pdf; HEV) } \\
\text { 'Bei Verdacht auf HIV-2 ist eine hochempfindliche HIV-2-NAT-Testung durchzuführen. }\end{array}$} \\
\hline
\end{tabular}

LoD der ID-NAT-Tests zum Ausschluss der Spenderin-

ektion

$\mathrm{NAT} \leq 100 \mathrm{IU} / \mathrm{m}$

Blutprodukten HIV-infiziert

Genomsequenzanalyse schließt phylogenetische Identität aus

Kein Nachweis von HBsAg, Anti-HBc oder HBV-Genom 16 Wochen nach der Spende bzw. der Gabe von Blutprodukten 

Blutprodukten HBV-infiziert

Genomsequenzanalyse schließt phylogenetische Identität aus

Blutprodukten HCV-infiziert

Genomsequenzanalyse schließt phylogenetische Identität aus

Kein Nachweis von HEV-Genom in der Nachuntersuchungsprobe der verdächtigten Spende und/oder kein Nachweis von

Genomsequenzanalyse schließt phylogenetische Identität aus

Blutprodukten WNV-infiziert

Genomsequenzanalyse schließt phylogenetische Identität aus

\section{Zielregion für die Genom-} sequenzanalyse zum Ausschluss der Virusidentität

\begin{tabular}{|c|c|c|c|}
\hline & $\begin{array}{l}\text { Ursächlichkeit des Blutprodukts für Empfängerinfektion } \\
\text { ausgeschlossen, wenn: }\end{array}$ & $\begin{array}{l}\text { LoD der ID-NAT-Tests zum } \\
\text { Ausschluss der Spenderin- } \\
\text { fektion }\end{array}$ & $\begin{array}{l}\text { Zielregion für die Genom- } \\
\text { sequenzanalyse zum Ausschluss } \\
\text { der Virusidentität }\end{array}$ \\
\hline HIV & $\begin{array}{l}\text { Kein Nachweis von Anti-HIV oder HIV-Genom } 12 \text { Wochen nach } \\
\text { der Spende bzw. der Gabe von Blutprodukten bei spendender } \\
\text { und/oder empfangender Person } \\
\text { - Empfangende Person war bereits zum Zeitpunkt der Gabe von } \\
\text { Blutprodukten HIV-infiziert } \\
\text { - Genomsequenzanalyse schließt phylogenetische Identität aus } \\
\text { (z.B. unterschiedlicher Subtyp) }\end{array}$ & $\begin{array}{l}\mathrm{NAT} \leq 100 \mathrm{IU} / \mathrm{ml} \\
(\mathrm{HIV}-1 \mathrm{RNA})^{c}\end{array}$ & $\begin{array}{l}\text { Polymerasegen (reverse Tran- } \\
\text { skriptase, Polymerase, Integrase } \\
\text { analog der Resistenztestung) und } \\
\text { zusätzlich, falls es keine eindeutige } \\
\text { Aussage gibt, noch den V3 Loop } \\
\text { (analog der Korezeptoranalyse) }\end{array}$ \\
\hline HBV & $\begin{array}{l}\text { Kein Nachweis von HBsAg, Anti-HBc oder HBV-Genom } 16 \\
\text { Wochen nach der Spende bzw. der Gabe von Blutprodukten } \\
\text { bei spendender }{ }^{\mathrm{a}} \text { und/oder empfangender Person }{ }^{\mathrm{b}} \\
\text { - Empfangende Person war bereits zum Zeitpunkt der Gabe von } \\
\text { Blutprodukten HBV-infiziert } \\
\text { - Genomsequenzanalyse schließt phylogenetische Identität aus } \\
\text { (z.B. unterschiedlicher Genotyp) }\end{array}$ & $\leq 5 \mathrm{IU} / \mathrm{ml}$ & ORF für das S-/Pol-Gen \\
\hline $\mathrm{HCV}$ & $\begin{array}{l}\text { Kein Nachweis von Anti-HCV oder HCV-Genom } 12 \text { Wochen } \\
\text { nach der Spende bzw. der Gabe von Blutprodukten bei spen- } \\
\text { dendera und/oder empfangender Person }{ }^{\mathrm{b}} \\
\text { - Empfangende Person war bereits zum Zeitpunkt der Gabe von } \\
\text { Blutprodukten HCV-infiziert } \\
\text { - Genomsequenzanalyse schließt phylogenetische Identität aus } \\
\text { (z.B. unterschiedlicher Genotyp) }\end{array}$ & $\leq 20 \mathrm{IU} / \mathrm{ml}$ & HVR1-codierende Region \\
\hline HEV & $\begin{array}{l}\text { Kein Nachweis von HEV-Genom in der Nachuntersuchungs- } \\
\text { probe der verdächtigten Spende und/oder kein Nachweis von } \\
\text { HEV-Genom und/oder einer Serokonversion nach der Gabe } \\
\text { von Blutprodukten bei empfangender Person } \\
\text { - Empfangende Person war bereits zum Zeitpunkt der Gabe von } \\
\text { Blutprodukten HEV-infiziert } \\
\text { - Genomsequenzanalyse schließt phylogenetische Identität aus } \\
\text { (z.B. unterschiedlicher Genotyp) }\end{array}$ & $\leq 50 \mathrm{IU} / \mathrm{ml}$ & $\begin{array}{l}\text { ORF1-Gen oder eine hypervariable } \\
\text { Zielregion in ORF2 (z. B.: nt } 5885 \\
\text { bis } 6510 \text { der GenBank-Sequenz } \\
\text { NC001434) }\end{array}$ \\
\hline WNV & $\begin{array}{l}\text { Kein Nachweis von WNV-Genom in der Nachuntersuchungs- } \\
\text { probe der verdächtigten Spende und/oder kein Nachweis von } \\
\text { WNV-Genom nach der Gabe von Blutprodukten bei empfan- } \\
\text { gender Person } \\
\text { - Empfangende Person war bereits zum Zeitpunkt der Gabe von } \\
\text { Blutprodukten WNV-infiziert } \\
\text { - Genomsequenzanalyse schließt phylogenetische Identität aus } \\
\text { (z.B. unterschiedlicher Genotyp) }\end{array}$ & $\leq 100$ Kopien/ml & $\begin{array}{l}\text { Vorzugsweise Gesamtgenom, } \\
\text { mindestens NS5-Gen }\end{array}$ \\
\hline \multicolumn{4}{|c|}{$\begin{array}{l}\text { as. Anhänge A2, A3, B2, C2, C3, D } \\
\text { 'labordiagnostischer Nachweis entsprechend den AWMF-Leitlinien (HIV, HCV, HBV) bzw. Empfehlungen der Europäischen Vereinigung für das Studium der Leber (EASL, } \\
\text { https://easl.eu/wp-content/uploads/2018/10/EASL-CPG-hepatitis-E-virus-infection.pdf; HEV) } \\
\text { 'Bei Verdacht auf HIV-2 ist eine hochempfindliche HIV-2-NAT-Testung durchzuführen. }\end{array}$} \\
\hline
\end{tabular}

Polymerasegen (reverse Transkriptase, Polymerase, Integras Aussage gibt, noch den V3 Loop 